\title{
Measuring Health System Performance: A Critique, with Proposals for Improving on the WHO "Building Blocks Framework"
}

\author{
Kai-Lit Phua*
}

School of Medicine and Health Sciences, Monash University Malaysia, Jalan Lagoon Selatan, 46150 Bandar Sunway, Selangor, Malaysia

\begin{abstract}
Attempts have been made to measure overall national health system performance and, more controversially, rank national health systems in terms of their relative performance. The World Health Organization made such an attempt in 2000. The resulting rankings generated criticism and controversy and was not repeated. Any attempt to measure overall national health system performance for the purpose of comparison is fraught with challenges and unlikely to be productive. In this critique (opinion piece), I argue that instead of measuring and ranking in terms of relative performance (such as "responsiveness of health system" and "fairness of contribution to the health system"), it would be relatively easier and less controversial to change the metrics and focus only on which components of a national health system are not meeting specific standards of minimal requirements (i.e. using benchmarks associated with the WHO "Building Blocks Framework") and ought to be improved through public policy intervention. The WHO Building Blocks Framework has shortcomings and omissions. Some suggestions for its improvement are proposed.
\end{abstract}

Keywords: Health system performance, metrics, performance standards, rankings, WHO Building Blocks Framework.

\section{INTRODUCTION}

Attempts have been made to measure overall national health system performance and, more controversially, rank national health systems in terms of their relative performance. The World Health Organization made such an attempt in 2000. The resulting rankings generated criticism and controversy and were not repeated [1-3]. Any attempt to measure overall national health system performance and then use these for cross-national comparison (through a system of rankings) is fraught with challenges and unlikely to be productive [4]. Related attempts such as studying the commitment of health policy-makers to key areas that are known to be linked to enhanced health system performance such as primary care, quality improvement and information technology, merely measure stated intent and not actual performance improvement per se [5].

Indeed, according to WHO [6] The existence of multiple analytical and strategic frameworks for health systems results in considerable potential for duplication, overlap and confusion. Existing frameworks include the WHO framework for health systems performance assessment (1); the World Bank control knobs framework (2); and the WHO building blocks framework (3). Such frameworks have varying starting points, resulting in emphases on different outcomes to be tracked.

A national health system can be examined in terms of various aspects such as:

*Address correspondence to this author at the School of Medicine and Health Sciences, Monash University Malaysia, Jalan Lagoon Selatan, 46150 Bandar Sunway, Selangor, Malaysia; Tel: (+603)-5514-6324;

Fax: (+603)-5514-6323; E-mail: phuak1@hotmail.com
- Human Resources

- Facilities

- Health information system (i.e. the systems used to collect data such as electronic health records, healthcare utilization, and so on)

- Technology (e.g. technology used in direct patient care such as imaging systems)

- Financing

- Governance and health policy

Instead of attempting to measure and rank national health systems in terms of relative performance (such as "responsiveness of health system" and "fairness of contribution to the health system"), my view is that it would be relatively easier and less controversial to change the metrics and focus only on which components of a national health system are not meeting specific standards of minimal requirements (benchmarks) and ought to be improved through public policy intervention. Similarly, a recent publication by the WHO focusing on the monitoring of the "building blocks" of health systems is probably a more productive way to proceed too [6]. The WHO building blocks include "essential medicines" (availability and access) but does not include "technology" specifically-except under the broad "health service delivery" building block.

\section{WHO'S "BUILDING BLOCKS FRAMEWORK": A CRITIQUE AND SUGGESTIONS FOR MODIFICA- TIONS AND IMPROVEMENTS}

The WHO's Building Blocks Framework (please refer to Appendix 1) includes the following: 
- Health Service Delivery

- Health Workforce

- Health Information

- Essential Medicines

- Health Financing

- Leadership and Governance

The scheme is interesting but appears to contain some shortcomings or omissions that can arguably be rectified with the inclusion of additional material.

\subsection{Suggestions for Modifications to the Health Service Delivery Building Block}

Countries can vary greatly by geographical size. Other things being equal, it is easier to plan and establish a properly-functioning network of health facilities for a small country than for a huge country. Duplication or unnecessary proliferation of certain health facilities or health services may also be costly and economically inefficient.

Hence, it is suggested to take into account the following:

Health facilities/population ratio in a specific geographical region of a country (i.e. sub-national unit such as a province, large city or sub-province): The Framework's core indicators for Health Service Delivery can be improved by taking into greater consideration the distributional (geographical) dimension. It is proposed here that this can be done by taking into account the availability of health facilities in relation to population within a specific geographical region (e.g. for convenience, a political jurisdiction such as a province, municipality or county). Of course, this will only make sense for primary, secondary and some types of tertiary health care facilities and not for specialized tertiary care facilities such as those for cardiac surgery (which are few in number and tend to be located in the capital city or the largest city). For the latter, it should be the ratio for large geographical units such as the entire nation.

Inpatient beds/population ratio in a specific geographical region: The case for this is similar to that for health facilities as discussed above and also subject to the same limitations, i.e. for beds for secondary care and some types of tertiary care but not for specialized or advanced tertiary care.

Thus, for specialized or advanced tertiary care, the metric can be "number of health facilities per 10, 000 population" for the entire country. But for lower levels of care, the metric should be "number of health facilities per 10, 000 population" for a province, large city or sub-province. The same logic can be applied to specialized inpatient beds versus ordinary inpatient beds.

\subsection{Suggestions for Modifications to the Health Workforce Building Block}

The metrics used in the WHO's Building Blocks and Indicators scheme (as listed in Appendix 1) can be improved by taking into consideration the public sector vis-à-vis the private sector. This is especially necessary in the case of countries where, historically, the public sector dominated but in more recent years, the private sector has been expanding significantly because of major policy changes such as privatization and liberalization in health care [7].
Health workforce in the public versus the private sector (taking into account workloads): It would be useful to measure the public sector-private sector distribution of doctors and their respective workloads and how these have changed over time [8]. For example, what percentage of specialists work in public sector hospitals and what percentage of all hospital patients they treat. This can be compared with the percentage of specialists who work in private hospitals and what percentage of all hospital patients they treat. In the case of Malaysia, only $30 \%$ of hospital specialists work in the public sector but they tend to $70 \%$ of all hospital admissions [9]. This phenomenon has been compounded by the continued outflow of experienced specialist doctors from public hospitals to the more lucrative private sector hospitals (the latter has been growing because of the Malaysian government's policy of encouraging privatization of medical care).

Distribution/composition of health workforce: It would be useful to measure the number of primary care physicians versus specialist physicians, and the number of specific specialists such as psychiatrists in relation to population. In the case of the former, if we look at the USA, the percentage of specialists is high and some of them are often providers of primary care. This is a sign that the specialist-PCP (primary care provider) ratio is unbalanced in the health workforce [10]. (It is also a sign of inefficient utilization of highly skilled human resources in that internal medicine specialists and obstetricians/gynecologists are used to treat routine health problems). In the case of the latter, a very low psychiatrist-population ratio would indicate the need for more psychiatrists. But the number of other personnel who provide similar services (although they do not have the legal authority to prescribe medication) such as clinical psychologists and mental health counselors should also be taken into consideration.

Doctor, nurse, pharmacist, other health professional emigration: If emigration of skilled health workers such as doctors and nurses is significant, this would be a sign that there are major problems in the healthcare system and the larger society. Thus, the fact that many Filipino nurses are migrating to work overseas, and more significantly, there are even Filipino doctors migrating to work as nurses overseas, indicate that there are serious problems in the health system of the Philippines [11]. The emigration of Greek physicians because of national economic turmoil is another example [12]. The WHO Building Blocks Framework omits measuring health professional emigration completely. This can be considered a major shortcoming of the scheme.

Doctor, nurse, pharmacist and other skilled health workers underemployment: If many skilled health workers are underemployed (holding multiple locum positions [13], working part-time although the preference is for full-time work [13], being employed in a job other than what they were trained for although they would prefer not to do so, e.g., a trained pharmacist working as a drug company salesperson), this would be a sign that the labor market for health workers is not functioning properly. There is a mismatch between supply and demand. Again, the WHO Building Blocks Framework omits looking at skilled health worker underemployment completely.

$\%$ of health workers who are foreign-born and also possess foreign credentials: This indicator is necessary as it 
shows the extent to which the health system is dependent on skilled immigrant labor. If also indicates how the health system (e.g. of the US or the UK) could be negatively affecting the health systems of sending countries such as the Philippines or South Africa. In other words, how less wealthy countries are de facto subsidizing wealthier countries [14]. It is necessary to combine both foreign birth and possession of foreign credentials since nationals of a particular developing nation may have a tradition of sending its workforce for higher education in its former colonial ruling power such as France or Britain.

\subsection{Suggestions for Modifications to the Health Informa- tion Building Block}

Quality of basic health data collected: To determine the health status of the population (and to measure improvement over time), it is necessary to collect fertility and mortality data and come up with basic data such as the infant mortality rate and the maternal mortality rate. The quality of the basic data should be investigated, e.g. through sample surveys and other demographic tools.

According to Moultrie [15], these basic types of possible testing procedures can be used to test the quality of data:

Consistency checks, based on one or more censuses;

Comparison of observed data with a theoretically expected configuration, e.g., the use of balancing equations and population projection models;

Comparison of data observed in one country with those of other countries;

Comparison with similar data obtained for nondemographic purposes;

Direct checks (e.g. re-enumeration of samples drawn from the larger population.

\subsection{Suggestions for Modifications to the Essential Medi- cines Building Block}

Existence of pharmacoeconomic evidence-based formulary in the public sector (with cost-effectiveness taken into consideration): A national formulary of essential drugs in the public sector is a necessity to promote rational drug use. However, drug use must also be cost-effective. Pharmacoeconomic evidence is necessary to promote costeffectiveness [16]. Thus, if the national formulary is not based on such evidence, this could be considered a weakness in the national health system. It should be pointed out that such principles must also apply to supplementary drug lists. A study on the experience of China showed the presence of "excessive and non-scientific selection of medicines" on supplementary drug lists drawn up by authorities in the provinces [17].

Drug prices compared to the rest of the world (nations with comparable Gross National Income per capita): If the prices - in Purchasing Power Parity dollars - of many essential drugs is significantly above that of other nations of comparable Gross National Income (GNI) per capita, this would be a sign that drug prices are too high [18]. The government could take action on this by negotiating with pharmaceutical companies or by carrying out "parallel imports" of such drugs to increase competition and lower drug prices.

\subsection{Suggestions for Modifications to the Health Financ- ing Building Block}

Healthcare cost inflation: If the rate of healthcare cost inflation is high, this would be a sign of problems in the health system, e.g., excessive market power on the part of providers (including insurance companies and other third party payers) such as in the USA's health system. Hence, it would be useful to include the measurement of healthcare cost inflation in the Health Financing Building Block.

Real per capita spending on health: If real (inflationadjusted) per capita spending on health is significantly below or above the norm for nations of comparable GNI per capita, this would indicate under-spending and over-spending (system inefficiency, wastage etc.) respectively.

$\%$ of GDP spent on health: Again if the \% of GDP spent on health is significantly below or above the norm for nations of comparable GNI per capita, this would indicate under-spending and over-spending (inefficiency, wastage etc.) respectively. The USA spends significantly more on healthcare than other high income countries. One reason for this is high administrative costs in American hospitals [19].

\subsection{Suggestions for Modifications to the Leadership and Governance Building Block}

Educational and professional qualification of key decision-makers such as the Minister of Health: I would argue that, ideally, the Minister of Health should possess some educational or professional credential in the area of public health (although he or she does not need to have a clinical medicine background). This would enable the Minister to better understand health challenges in the country and formulate more effective health and public health policies. Public health training would enable the Minister to see beyond the conventional concerns of the lay public, i.e., the building of more public clinics and public hospitals and focusing mainly on increasing access to clinical services.

\section{CONCLUSION}

Measuring health system performance is a challenging task. Measuring health system performance for the purpose of comparison and ranking vis-à-vis those of other nations is not only controversial but also appears to be unproductive too. In this paper, I argue that it would be relatively easier and more useful to change the metrics and focus only on which components of a national health system are not meeting specific standards of minimal requirements, using benchmarks derived from schemes such as the WHO "Building Blocks Framework". Once identified, public policy intervention can be undertaken to bring about improvement. However, the WHO Building Blocks Framework is not without its shortcomings and deficiencies. I propose some suggestions for its improvement, e.g., including measurement of skilled health professional emigration, skilled health worker underemployment, reliance of the national health system on foreign health workers ( $\%$ of health workers who are foreign-born and also possess foreign credentials), domestic drug prices compared to the rest of the world, healthcare cost inflation, etc. 


\section{CONFLICT OF INTEREST}

The author confirms that this article's content has no conflict of interest.

\section{ACKNOWLEDGEMENTS}

Declared none.

\section{APPENDIX 1: THE WORLD HEALTH ORGANIZA- TION "BUILDING BLOCKS" FRAMEWORK (EXIST- ING INDICATORS)}

\section{Health Service Delivery}

Number and distribution of health facilities per 10, 000 population

Number and distribution of inpatient beds per 10, 000 population

Number of outpatient department visits per 10, 000 population per year

General service readiness score for health facilities.

Proportion of health facilities offering specific services.

Number and distribution of health facilities offering specific services per 10, 000 population.

Specific-services readiness score for health facilities.

\section{Health Workforce}

Number of health workers per 10, 000 population

Distribution of health workers by occupation/specialization, region, place of work and sex

Annual number of graduates of health professions educational institutions per 100, 000

population, by level and field of education.

\section{Health Information}

Health information system performance index.

\section{Essential Medicines}

Average availability of 14 selected essential medicines in public and private health facilities

Median consumer price ratio of 14 selected essential medicines in public and private health facilities.

\section{Health Financing}

Total expenditure on health

General government expenditure on health as a proportion of general government

expenditure (GGHE/GGE)

The ratio of household out-of-pocket payments for health to total expenditure on health.

\section{Leadership and Governance}

Policy index

This table is adapted from:

WHO. Monitoring the building blocks of health systems: a handbook of indicators and their measurement strategies. Geneva: World Health Organization, 2010. pp. xi-xii.

\section{REFERENCES}

[1] World Health Organization. World health report. Geneva: WHO; 2000 .

[2] Evans DB, Tandon A, Murray CJL, Lauer JA. Comparative efficiency of national health systems: cross national econometric analysis. BMJ 2001: 323(7308): 307-10

[3] Wagstaff A. Measuring equity in health care financing. World Bank Policy Research Working Paper 2550. Washington, DC: World Bank; 2001

[4] Hadad S, Hadad Y, Simon-Tuval T. Determinants of healthcare system's efficiency in OECD countries. Eur J Health Econ 2013; 14(2): 253-65.

[5] Gauld R, Burgers J, Dobrow M, et al. Healthcare system performance improvement: a comparison of key policies in seven highincome countries. J Health Organ Manag 2014; 28(1): 2-20.

[6] World Health Organization. Monitoring the building blocks of health systems: a handbook of indicators and their measurement strategies. Geneva: WHO, 2010.

[7] Chee HL, Barraclough S, Eds. Health care in Malaysia: the dynamics of provision, financing and access. London and New York: Routledge; 2007.

[8] Chee HL. Current healthcare financing issues in Malaysia. Asia Research Institute Working Paper Series No. 18. Singapore: Asia Research Institute, National University of Singapore; 2004.

[9] Chan CK. Re-inventing the welfarist state? The Malaysian health system in transition. J Contemporary Asia 2010; 40(3): 444-65.

[10] Sandy LG, Bodenheimer T, Pawlson LG, Starfield B. The political economy of U.S. primary care. Health Affairs 2009; 28(4): 1136 45.

[11] Lorenzo FM, Galvez-Tan J, Icamina K, Javier L. Nurse migration from a source country perspective: Philippine country case study. Health Serv Res 2007; 42(3 Pt 2): 1406-18.

[12] Ifanti AA, Argyriou AA, Kalofonou FH, Kalofonos HP. Physicians' brain drain in Greece: a perspective on the reasons why and how to address it. Health Policy 2014; 117(2): 210-5.

[13] Frechette D, Hollenberg D, Shrichand A, Jacob C, Datta I. What's really behind Canada's unemployed specialists? Too many, too few doctors? Findings from the Royal College's employment study. Ottawa: Royal College of Physicians and Surgeons of Canada; 2013.

[14] Starfield B, Fryer Jr GE. The primary care physician workforce: ethical and policy implications. Ann Fam Med 2007; 5(6): 486-91.

[15] Moultrie TA. [Internet]. General assessment of age and sex data. In Moultrie TA, RE Dorrington, AG Hill, K Hill, IM Timæus, B Zaba, Eds. Tools for demographic estimation. Paris: International Union for the Scientific Study of Population, 2013. Available from: http://demographicestimation.iussp.org/content/generalassessment-age-and-sex-data [accessed 8 December 2013].

[16] Suh DC, Okpara IR, Agnese WB, Toscani M. Application of pharmacoeconomics to formulary decision making in managed care organizations. Am J Manag Care 2002; 8(2): 161-9.

[17] Tian X, Song Y, Zhang X. National Essential Medicines List and policy practice: a case study of China's health care reform. BMC Health Serv Res 2012; 12: 401.

[18] Babar Z, Ibrahim MI, Singh H, Bukhari NI. The reality of medicine prices in Malaysia. Penang: Penerbit Universiti Sains Malaysia; 2010 .

[19] Himmelstein DU, Jun M, Busse R, et al. A comparison of hospital administrative costs in eight nations: US costs exceed all others by far. Health Affairs 2014; 33(9): 1586-94.

Received: July 15, 2014
(C) Kai-Lit Phua; Licensee Bentham Open.

This is an open access article licensed under the terms of the Creative Commons Attribution Non-Commercial License (http://creativecommons.org/licenses/by-nc/3.0/) which permits unrestricted, non-commercial use, distribution and reproduction in any medium, provided the work is properly cited. 